\title{
Literature overlaps and gaps between the fields of knowledge management and humans resource development
}

Rob Mayes, Robin Tamez, and Jeff Allen

College of Information, University of North Texas,

Denton, Texas, 76207 USA E-mail: Jeff.Allen@unt.edu 


\section{Purpose}

To identify the multidisciplinary processes, models, and theories common to both Knowledge Management (KM) and Human Resource Development (HRD). 


\section{Theoretical Framework}

- The conceptual framework of this chapter was based on the theory that KM shares with HRD an inherent concern with the development of human capital as the primary source of an organization's intelligence . (Tamez, Mayes \& Allen, 2013). 


\section{Potential Areas of Commonality}

Table 1. Potential Parallel Processes between KM and HRD strategies.

Knowledge Management

KM Needs Analysis/Gap Analysis

Knowledge Repository Design-

Development

Implement KM Systems and Train Users

Evaluate KM System Effectiveness
Human Resource Development

HRD Needs Analysis/Gap Analysis

Instructional Design-Development

Knowledge and Skills Transfer

Evaluate HR Performance Levels 


\section{Methodology}

Callaha the method Callahan methodolog replicability integrated 1 fields $(\mathrm{KM}$ search perid 2010 and 2 a list of fou established the results demonstrate
We chose four prominent journals in each of the fields (KM and HRD). We conducted the searches in August of 2017. The search period parameters were limited to articles published between the years 2010 and 2016. We conducted searches using ProQuest and EBSCO to establish a list of four predominant academic journals for both $\mathrm{KM}$ and HRD. ist document

rly literature. -documented validity and conduct this each of the f 2017. The en the years $p$ to establish RD. After we cross check articles that 


\section{HRD in KM}

Table 2. KM Articles Overlapping into HRD

\begin{tabular}{lcrr}
\hline \multicolumn{1}{c}{ Knowledge Management Journal Titles } & N & All Text Results & Abstract Results \\
\hline Journal of Knowledge Management & 1087 & 75 & 3 \\
Journal of Intellectual Capital & 625 & 30 & 1 \\
Knowledge Management Research \& Practice & 564 & 1 & 1 \\
International Journal of Knowledge & 115 & 8 & 1 \\
Management & & 114 & 5 \\
\hline Totals & 2391 & & \\
\hline
\end{tabular}

Note: Search Criteria: "Human Resource Development" 


\section{$\mathrm{KM}$ in $\mathrm{HRD}$}

Table 3. HRD Articles Overlapping into KM

\begin{tabular}{lrrr}
\hline Human Resource Development Journal Titles & N & All Text Results & Abstract Results \\
\hline Human Resource Development Quarterly & 2452 & 66 & 8 \\
Human Resource Development International & 1907 & 122 & 14 \\
Advances in Developing Human Resources & 637 & 44 & 16 \\
Human Resource Development Review & 411 & 23 & 1 \\
Totals & 5407 & 255 & 39 \\
\hline
\end{tabular}

Note: Search Criteria: "Knowledge Management" 
What Now?

This is ongoing work ...

but we have some

systems-based thoughts. 
- $\mathrm{KM}$ is the working brain of an organization acquiring, storing, and disseminating information so that decisions are made in intelligent and informed ways.

- HRD acts as the nervous system for sensing and delivering the information to and from the brain for acquiring and retrieving knowledge.

Turner, Zimmerman, and Allen (2012) describe this phenomenon for the application of knowledge capitalization as organizational intelligence. 
IN COLLEGE OF
INFORMATION

UNT
CENTER FOR KNOWLEDGE SOLUTIONS

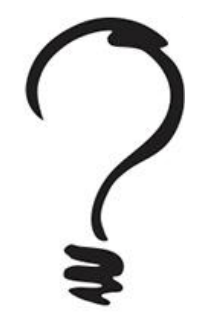

GENERATE •INTEGRATE $\bullet$ DISSEMINATE

\section{For More Information:}

\section{Jeff Allen}

College of Information

Department of Information Science

University North Texas,

E-mail: Jeff.Allen@unt.edu

www.sageprofessor.com 